poses we have appended to Table 1 the published frequency ${ }^{4}$ for an ammonia maser employed at Laboratoire Suisse de Recherches Horlogères, Neuchâtel, using another re-setting criterion. The frequency of this maser is considerably lower than that of Maser No. 5 and illustrates the fact that it is possible to operate ammonia masers with considerably different but yet highly stable oscillation frequencies.

We wish to thank the Director of the National Physical Laboratory for making available the results of the maser/cæsium comparisons obtained at Teddington. This communication is published with the permission of the Chief Scientist, Ministry of Aviation, and the Engineer-in-Chief, Post Master General's Department, Commonwealth of Australia. A. M. J. Mitcheli. Signals Research and Development Establishment, Ministry of Aviation, Christchurch, Hants.

$$
\text { E. SANDBACH }
$$

Research Laboratories,

Post Master General's Department, 59 Little Collins Street, Melbourne, C.1.

1 Mitchell, A. M. J., Roots, K. G., and Phillips, G., "Electronic Technology" (to be published).

2 Barnes, F. S., Proc. Inst. Rad. Eng., 47, 2085 (1959).

3 Essel, L., and Parry, J. V. L., Trans. Roy. Soc., 250, 45 (1957)

- Observatoire de Neuchâtel, Suisse, Circulaire No. 2 (May 1959).

\section{Monocular 'Rivalry' between Stabilized and Unstabilized Retinal Images}

Ir is well known that images stabilized against retinal tremor tend to fade from vision ${ }^{1,2}$, and it has been suggested that this indicates some form of fatigue or adaptation in the retinal receptors, which is normally relieved by small irregular displacoments of the image. When using a simple stabilizing device ${ }^{3}$ for the study of complementary patterns ${ }^{4}$, I have observed a related effect which seems to require further, if not different, explanation.

The apparatus ${ }^{3}$ comprises a close-fitting contact lens with an optical power of 60 dioptres, supporting a light 'Dural' tube on which objects under examination are mounted at the focal distance of about $1 \frac{1}{2} \mathrm{~cm}$. The lens incorporates an artificial pupil $4 \mathrm{~mm}$. in diameter. When the image of a sharply black-andwhite object such as my 'ray' figure ${ }^{4}$ is thus stabilized on the retina, fading is much less pronounced and permanent than with more delicate and irregular gradations of stimulus intensity ${ }^{2}$.

The observation in question is as follows. When a thin objcct, such as a wire the diametex of which subtends perhaps $10^{\prime}$, is viewed in silhouette, it often remains visible for some time. If, however, an object giving an unstabilized image, such as the finger-tip, is now brought up just behind the wire to the focal zone of the stabilizing lens, a striking change takes place. The stabilized wire disappears as a whole, and the finger-tip appears completely visible, as if nothing were between it and the eye. The impression is similar to that given by binocular rivalry between disparate images in left and right eyes. When the finger is removed, the wire reappears.

With stabilized objects of increasing width, it is necessary (as might be expected) to scan the unstabilized background with an increasing amplitude if the objects are to disappear from view, and a limit is reached (dependent partly on the structure of the background) beyond which total disappearance does not occur.

It may well be suspected that the reluctance of the wire (and indeed of the 'ray' figure) to disappear. permanently when stabilized is due in part to im. perfect stabilization. This I leave an open question, though it may be remarked that with apparatus which presents the stabilized image within an unstabilized frame ${ }^{1,2}$ it would now seem unsafe to use extinction of the image as a criterion of stability. What seems significant is that one can cause the disappearance-sudden and complete-of a thin stabilized object merely by presenting it against an unstabilized background. Together with the inhibition of extinction by regularity and boldness in the stabilized pattern this raises doubts whether changes in retinal receptors alone are responsible for the normal fading. On a retinal theory one might have expected that the addition of an unstabilized background would revive activity in neighbouring receptors adapted to a stable image by disturbing them, as flickering light is found to $\mathrm{do}^{5}$.

It is difficult to see how it could predict the opposite effect actually observed, particularly the simultaneous and sudden disappearance of all parts of the wire. For this the idea of fatigue or adaptation among primitive gestalt-forming mechanisms would seem worthy of exploration.

\section{Wheatstone Physics Laboratory, King's College,}

London, W.C.2. Jan. 28.

${ }^{2}$ Ditchburn, R. W., and Ginsborg, B. L., Nature, 170, 36 (1952).

${ }^{2}$ Riggs, L. A., Rateliff, F., Cornsweet, J. C., and Cornsweet, T. N. J. Opt. Soc. Amer., 43, 495 (1953).

${ }^{3}$ Mackay, D. M., Nature, 180, 1145 (1957)

"MacKay, D. M., Nature, 180, 849 (1957).

${ }^{5}$ Ditchburn, R. W., and Fender, D. H., Opt. Aet., 3, 128 (1955).

\section{GEOPHYSICS and GEOLOGY}

\section{Palæomagnetism in Antarctica}

WE have recently measured the direction of magnetization of two dolerite sheets and ten basic dykes in the Wright Valley (lat. $77.5^{\circ} \mathrm{S}$., long. $161.5^{\circ} \mathrm{E}$.) of South Victoria Land. The dykes intrude the basement granite in the area but do not cut the overlying Beacon Sandstone. The dolerite sheets are intruded into the basement and in some places cut the Beacon Sandstone. They post-date the dykes and the sandstone. The directions and relevant statistics are given in Table 1.

There is good evidence that the directions of magnetization are stable. The divergences of the mean directions of both sheets and dykes from the present Earth's field and the dipole field exceed the errors $(P=0.05)$ by a factor of 3 or more. The coercivity of saturation isothermal remanence is high, varying from 600 to 1,200 œrsteds. Treatment in alternating magnetic fields of up to 370 orsteds (peak) produced only small changes in the directions of magnetization. In some cases the directions remained little changed in alternating fields up to 750 œrsteds. These changes vary between $2^{\circ}$ and $5^{\circ}$ and are of the same order as the experimental error.

Other pole results from Antarctica have recently been reported by Nagata and Shimizu ${ }^{1}$ from the PreCambrian gneiss of Ongul Island (namely, lat. $3^{\circ} \mathrm{N}$., 